FOR those of my generation who studied plant physiology during and immediately after the second World War choice of textbooks was extremely limited. Now the situation has changed dramatically and students in the 1980s have a wide range of attractive texts some of the more successful of which have recently appeared in new editions. Comparison of a lavishly illustrated modern textbook such as Bidwell's Plant Physiology with those that were available to me in the 1940 s shows how much the standards of book production have improved in the intervening years.

A popular successor to James' $A$ n Introduction to Plant Physiology as an introductory text is Baron's Organization in Plants. First published in 1963 the book has been extensively revised for the third edition. Like his predecessor, Baron places great emphasis on the encouragement of practical work and it is good to see graphs summarising data obtained in class experiments illustrating the text. An appendix gives details of a number of experimental procedures which should be well within the scope of most school laboratories, and a useful starting point for student projects. Some advice about the design of experiments and simple statistical procedures for the analysis of results would be a welcome addition to this section. A new chemical nomenclature, which I assume is now being taught in schools, is used throughout the book. I suppose that we shall all get used to it in time, but is it really wise to call acetaldehyde ethanal which can be so easily confused with ethanol, however logical it might seem to be? It is something of a relief to be informed that acetic acid for some unexplained reason is still acceptable to the powers that be.

Nowadays a problem for writers of plant physiology textbooks is the lack of general botanical knowledge among their readers because the teaching of traditional botany in schools has almost ceased. To overcome this, Baron provides some background information about the structure of plant cells, but for vital details of plant anatomy the student must go elsewhere. It is a pity that the list of books for further reading at the end of chapter 1 does not include a textbook of general anatomy.

Bidwell's Plant Physiology, the first edition of which appeared in 1974, is one of several excellent textbooks by North American authors which give comprehensive coverage of the whole field of plant physiology at a fairly advanced level. Although like most other contemporary texts it concentrates mainly on the physiology of flowering plants with particular reference to those crop plants which have been studied intensively, there is a section devoted to the physiology of what are described as "special" organisms. These include trees, as one might expect from a Canadian-based author, macroscopic algae, parasites and symbionts. In keeping with modern trends space is found for such topics as the effects of stress on plant growth and the influence of man on his environment.

Students who wish to learn more about the physiology of trees should turn to Kramer and Kozlowski's Physiology of Woody Plants. This book is an amalgamation and up-dating of two earlier books by the same authors. It is written primarily for foresters and arborists but inevitably it contains a good deal of general physiology. Biochemical topics are reviewed rather briefly and the book concentrates on more physiological and ecological aspects of plant physiology. There are useful chapters on the structure of wood and the characteristics of tree

\section{How plants work}

\section{James Sutcliffe}

Plant Physiology. By R. G. S. Bidwell. Second edition. Pp.726. (CollierMacmillan: London and Basingstoke; Macmillan: New York, 1979.) £14.25; $\$ 18.95$ in USA. Organization in Plants. By W. M. M. Baron. Third edition. Pp.264. (Edward Arnold: London; University Park Press: Baltimore, 1979.) Paperback £6.75.Physiology of Woody Plants. By P. J. Kramer and T.T. Kozlowski. Pp.811. (Academic: New York and London, 1979.) \$35; £22.75. Plant Metabolism. By G. Richter. Pp.475. (Croom Helm: London, 1979.) £11.95. Plant Metabolism. By H. D. Kumar and H. N. Singh. Pp.302. (Macmillan: London and Basingstoke, 1979) Paperback $£ 4.95$. The Control of Growth and Differentiation in Plants. By P. F. Wareing and I. D. J. Phillips. Second edition. Pp.347. (Pergamon: Oxford, 1979.) Hardback $£ 15$; paperback $£ 7$. Water Flow in Plants. By J. A. Milburn. Pp.225. (Longman: London and New York, 1979.) Paperback $£ 6.75$.

growth. A final chapter is concerned with the influence of environmental factors and cultural procedures on the productivity of forests and orchard crops. The text is supported by a large amount of experimental data and in addition to a substantial list of general references at the end of each chapter there is a bibliography of some 2,200 titles.

Plant biochemistry has been the subject of several new textbooks recently, among them Gerhard Richer's Plant Metabolism. This is an English (Americanised) translation of an apparently successful German textbook, Stoffwechsel Physiologie der Pflanzen, which was first published in 1969. Although the text has been revised for the English edition the more recent references quoted are to papers published in 1973 so that in certain areas of this rapidly advancing field the book is already somewhat out-of-date. More than a third of the volume is taken up by an account of photosynthesis which is well presented with the help of clear informative diagrams. The remainder of the book deals with such topics as respiration, the biosynthesis of cellular components and metabolic regulation in a straightforward and fairly conventional manner. No attempt is made to relate metabolic processes to growth but there is a brief incursion into plant water and ion relations and a section is devoted to the role of anions and cations in metabolism.

Extensive use is made of small print when describing experimental procedures and historical aspects of the subject. This enables the author to get much more information into a book of modest dimensions than would otherwise have been possible. However, this and the liberal use of italics throughout the text give the book a rather outdated look which I do not feel will appeal to American readers for whom it is apparently intended.

At less than half the cost of Richter's book one may obtain Kumar and Singh's Plant Metabolism which covers very similar ground at about the same level. The new edition of a book which was first published in India in 1976 has been printed there and does not reach the high standard of book production that we have come to expect from the publishers. Again quite a large part of the text is concerned with photosynthesis and as both authors have worked on unicellular algae it is not surprising that algal research features prominently in their account; but there is an adequate treatment of the various pathways of carbon assimilation in higher plants too. The rest of the book is less than inspired, being in the main a rather pedestrian account of the metabolism of nitrogen and sulphur, nucleic acids, proteins, lipids and secondary plant products. In the preface, the authors urge their readers to consult original papers but they provide very little incentive by failing to capture in their writing much of the excitement of biochemical research. Their rather unselective suggestions for further reading including, for example, several outdated textbooks and reviews, are not particularly helpful.

A large part of plant physiology is concerned with the processes of growth and development and there are several textbooks devoted entirely to this subject. One of the most popular of these in recent years has been Wareing and Phillips' The Control of Growth and Differentiation in Plants which was first published in 1970. The book is mainly concerned with the effects of plant growth regulating substances on various facets of plant growth. In the second edition the material has been re-organised and parts of the text 
have been revised in the light of developments in the intervening years. A comparison of the two editions indicates that apart from advances in understanding of the role of phytochrome in photomorphogenesis, which now merits a separate chapter, and the control of flowering there have been no outstanding discoveries in this field during the 1970's. It must have been somewhat depressing for the authors to find that so many of their pious hopes of advances expressed in 1970 remain unfulfilled in 1978 . I think that in the second edition I would have felt inclined to alter the form of words a little and explain why certain problems have remained surprisingly intractable. The picture is not perhaps quite so black as Wareing and Phillips have made it appear because they do less than justice to the notinconsiderable advances that have been made in the intervening years in knowledge of control mechanisms at the enzyme level. Fortunately there are other books which remedy this deficiency.

One of the most difficult subjects to put over to students of plant physiology is water relations. Teaching this subject is not helped by the less than adequate treatment of it in many textbooks. Authors of such books would do well to read Milburn's stimulating book on Water Flow in Plants before revising this section of their works. Milburn begins by describing the properties of water and he gives a clear account of the concept of water potential before going on to describe various kinds of apparatus by means of which water movement can be studied. He then describes the water relations of cells and traces the pathways of movement through the soil-plant-air continuum. There is an interesting chapter on responses to water stress and a description of a new device "the oil bomb" which may prove helpful for studying effects of stress on growth.

There is a useful set of appendices containing lists of symbols, units, physical data etc., and a series of numerical problems which will exercise the minds of some university teachers and tutors as well as their students.

James Sutcliffe is Professor of Plant Physiology in the University of Sussex, Brighton, UK.

\section{Vegetation productivity}

Melvin G.R. Cannell

Vegetation Productivity. By G. Jones. Pp.100. (Longman: Harlow, UK, 1979.) Paperback £3.95.

THIS little book is an attempt by a geographer to introduce people without any knowledge of plant science to the subject of vegetation productivity in different environments and the ways in which that productivity can be measured. The book is easy to read and may satisfy geography students, but it adds nothing to the books already available on this subject.

Chapter 1 is a introduction to plant physiology, misleadingly entitled "The measurement of plant growth". None of the concepts of plant community productivity are discussed, and photosynthesis itself gets only a brief mention. Chapters 2 and 3 on vegetation productivity contain useful reviews, but readers wanting accurate, balanced and more comprehensive accounts will need to refer to Cooper's book (Photosynthesis and Productivity in Different Environments. International Biological Programme 3, Cambridge University Press, 1975) which is not mentioned. Also, anyone seriously interested in measuring forest or grassland productivities will need the handbooks prepared by Newbould (Methods for Estimating the Primary Production of Forests. International Biological Programme, Handbook No. 2, Blackwell: Oxford, 1967) and Milner and Hughes (Methods for the Measurement of Primary Production of Grassland. International Biological Programme Handbook No. 6, Blackwell: Oxford, 1968) which form the bases of chapters 4 and 6 , respectively. Chapter 5 describes the author's work on forest growth in relation to soils, and chapter 7 offers some conclusions.

It is a pity that this book was not coauthored or edited by a plant scientist: vegetation is said to "produce" calories (page 14), transpiration is confused with respiration (page 19), a linear regression is said to follow a curve (page 55), and so on. Many figures and tables are poorly explained and both metric and imperial units are used. Furthermore, the thesis of the book, that a natural plant community provides a measure of the upper limit of vegetation productivity in a given environment, is, at best, highly contentious.

Melvin G.R. Cannell is Principal Scientific Officer and Tree Crop Physiologist at the Institute of Terrestrial Ecology, Penicuik, UK.

\section{Plant \\ diseases}

\section{I.M. Smith}

Epidemiology and Plant Disease Management. By J.C. Zadoks and R.D. Schein. Pp.427. (Oxford University Press: Oxford and New York, 1979.) £13.50. Atlas and Manual of Plant Pathology. By E.H. Barnes. Pp.325. (Plenum: New York and London, 1979.) £12.35.

IT is a pleasure to welcome Zadoks' and Schein's textbook. Plant disease epidemiology has developed enormously in theory and practice in the last twenty years, and the ideas of management in plant protection are spreading from pests to diseases. No university plant pathology course can now fail to tackle these new developments. This new text, though possibly not quite a primer for students with only basic knowledge, provides an excellent introduction to the subject for advanced students. As the authors suggest, the student can choose to benefit from any of the attractive self-contained chapters. They will at all times find clarity of exposition and an interesting and engaging style.
The work builds from the basic level of single infection cycles (monocyclic processes), through population phenomena (polycyclic processes), to the whole pathosystem and its management. It builds from the basic methods of disease control to their integration, from the familiar to the less familiar. It is realistic and critical, and pleasantly free from mysterious jargon.

The core chapter on the essential concepts of epidemiology and their mathematical background is clearly developed and well illustrated, presenting few problems to the not very mathematical reader. There is an excellent chapter on disease and crop loss assessment. Chapters on "Ecological concepts in plant pathology" and "Matters of scale" bridge the sections, the former providing useful comparisons with general ecological concepts.

The text does not make any attempt to deal with the techniques or apparatus of epidemiology, which are perhaps somewhat beyond its scope. However, practical considerations are well in evidence, especially in the assessment chapter, and a most useful feature is the inclusion of simple argued examples from the literature. Many chapters conclude with a useful set of exercises. In conclusion, this is an excellent reasonably priced textbook which will certainly find very wide use in advanced courses in plant 